\title{
Sign Bilingual Co-Enrollment Programs as Pathways to Ibasho
}

\author{
Jennifer M. McGuire*
}

\begin{abstract}
"Accessibility" features promote inclusive education but do not guarantee it. Communication accessibility, such as sign language interpretation or note-taking, may facilitate the academic inclusion of deaf students in general classrooms but does not necessarily enable their full social inclusion. Whereas in general classrooms deaf students are often the only deaf person present, in co-enrollment programs a "critical mass" of deaf students is educated alongside their hearing peers. These co-enrollment programs may employ a wide range of communication modalities; however, sign bilingualism has the greatest potential to create a socially inclusive environment, because deaf and hearing children can communicate directly without mediation. In this article, I explore the potential of sign bilingual co-enrollment programs as pathways to belonging, or ibasho, in Japanese education. The analysis is based on existing research on co-enrollment practices across the globe, an in-depth interview and ongoing correspondence with one of the founding members of the first co-enrollment program in the world, as well as my long-term fieldwork with deaf communities in Japan. Based on these findings, I argue that sign bilingual co-enrollment environments go beyond cosmetic accessibility to true inclusivity, creating opportunities for peer interactions, meaningful communication, and belonging.
\end{abstract}

Keywords: co-enrollment, deaf, inclusion, sign bilingualism, ibasho

\section{Sign Bilingual Co-Enrollment Programs as Pathways to Ibasho}

\section{Introduction}

School as an ibasho, or "place where one experiences belonging," is important for all

\footnotetext{
* Department of Sociology, Doshisha University, e-mail: jmcguire@mail.doshisha.ac.jp
} 
children and youth. It is especially critical for students who do not experience ibasho within their homes. Despite parents' best intentions, deaf children often face barriers to belonging within the family. Deafness is classified as a low incidence "disability," and deaf children are born to two hearing parents in approximately $90-95 \%$ of cases. Therefore, deaf children differ from children from other marginalized groups in Japan, such as Ainu and ethnic Koreans, who have the potential to share an inherited identity, even if they choose to reject or conceal it. ${ }^{\mathrm{i}}$ Hearing parents are unlikely to have much knowledge of deafness before welcoming a deaf child into their family and are rarely encouraged to develop an understanding of sign language or the cultural aspects of deafness. According to the prevailing medical model of deafness in Japan (which positions medical intervention, such as cochlear implantations, hearing aids, and speech therapy as "cures"), deafness is categorized as a disability and oral communication should be prioritized. This deficit view of deafness does not consider deaf children to be members of a linguistic community.

Communication is simultaneously a barrier and an equalizer for deaf children and youth. Deaf youth have described "shallow communication" and a lack of understanding in hearing families (McGuire 2017, 2020). They experience what has metaphorically been termed "dinner table syndrome" (Hauser et al., 2010; Meek, 2020) in which deaf people become lost in the flow of dialogue not only at the dinner table but also in various group situations within the family. These experiences may be mirrored in general education settings where group communication, rapid turn-taking, and simultaneous speech render lip-reading ineffective. Social integration has been defined as "the ability to interact with, make friends with, and be accepted by peers" (Stinson \& Antia, 1999; 169). Central to deaf students' ability to develop friendships (as well as to participate in academics) is their ability to communicate (McCain \& Antia 2005). Inaccessible oral communication can hinder deaf students' participation to the point of disabling them. Conversely, accessible communication can facilitate social integration and ultimately foster ibasho.

Creating ibasho is especially important for children with disabilities who face stigma and other difficulties in interpersonal relationships (Kayama, Haight 2014;13). In this article, ibasho are considered safe places where deaf students are engaged in mutually intelligible communication, accepted by peers, and positioned as members, not visitors, in the classroom-all of which lead to positive self-esteem and identity as a deaf person. For most deaf students, sign language is needed for this mutually intelligible communication to occur.

Language is central to any discussion of deaf education. Deaf students fall under the broad category of "students with disabilities" according to MEXT, but possess a unique profile which includes linguistic rights and cultural belonging. The UN Convention on the Rights of Persons with Disabilities (UN CRPD), which Japan signed in 2007 and ratified in 2014, pushes for the inclusion of students with disabilities in local schools but also demonstrates the "sensory exception" and importance of sign language for deaf students (Murray et al. 2018). Yet the World Federation of the Deaf (WFD) estimates that only one to two percent of deaf people are educated through sign language (WFD 2020).

Likewise, in Japan, only a small percentage of students are in Japanese Sign Language 
(JSL) environments. There is only one bilingual-bicultural school for the deaf in Japan, Meisei Gakuen. Students in most special needs schools will be exposed to a form of SimCom (Simultaneous Communication) in which a signed modality (Signed Japanese) is combined with speech. Students in mainstream schools are most likely educated and socialized in oral communication environments. The latter placement (mainstream schools) is becoming the norm. Special needs education schools for hearing support (formerly schools for the deaf) are seeing a decrease in enrollment year upon year, due to advancements in hearing technology along with a shift toward "inclusive education." In the past two decades, Japan has been emphasizing inclusive education, beginning with the revision to the School Education Act in 2007 which saw the establishment of a new system called special support education (tokubetsu shien kyōiku) with a focus on "equal opportunity," individual needs, and inclusion (see discussion of inclusive education in Mithout, 2016). Following the ratification of the UN CRPD in 2014, Japan aligned domestic laws in 2016 through the Act for Eliminating Discrimination against Persons with Disabilities (Shōgaisha sabetsu kaishōhō) which calls for "reasonable accommodations" (gōriteki hairyo) to remove social barriers in places of work and education for people with disabilities. In mainstream schools this may consist of note-taking (by hand or by computer), captioning, and, rarely, sign language interpretation.

The education of deaf students is often seen as an "either/or" choice: either they are educated in special schools among deaf peers or in regular schools among hearing ones. Either they can experience social inclusion in schools for the deaf or academic inclusion in regular schools. Yet there is a third path: academic and social inclusion in co-enrollment programs where a "critical mass" of deaf students studies together with hearing students in an inclusive environment within a general education setting. I argue that co-enrollment may provide a pathway to belonging for deaf students enrolled in mainstream schools in Japan, particularly when a sign bilingual model is implemented.

Below, I introduce educational placements in Japan and co-enrollment programs as a possible alternative to the current educational placements. Then I discuss how deaf students typically lack ibasho in "regular" classrooms. Next, I present the potential for ibasho through social inclusion in co-enrollment programs. I highlight the self-affirming dimension of sign bilingual programs (Japanese and JSL in Japan), which, I argue, have the greatest potential for ibasho creation. Finally, I address some of the challenges and considerations related to implementing sign bilingual co-enrollment programs. My analysis is based on existing research on co-enrollment practices across the globe, ${ }^{\text {ii }}$ an in-depth interview and ongoing correspondence with one of the founding members of the first co-enrollment program in the world, and my long-term fieldwork with deaf communities in Japan. Based on these findings, I argue that sign bilingual co-enrollment environments go beyond cosmetic accessibility into true inclusivity, creating opportunities for peer interactions, meaningful communication, and belonging. While this discussion pertains directly to deaf students, the principles of co-enrollment could be considered for other marginalized students in Japan who may ordinarily be faced with assimilative pressures and lack ibasho. 


\section{The "Philosophy" of Co-enrollment}

The ASL (American Sign Language) sign for co-enrollment combines the signs for "equal" and "study." "iii Co-enrollment has been described as both an "infusion strategy" in which the learning environment is changed (Kirchner 1994; 163) and an "overarching philosophy" (C. J. Kirchner, personal communication, Sept. 28, 2020). The philosophy centers on the belief that deaf children should be full members - not visitors - in mainstream classrooms and placed on "equal footing" with their hearing peers (Kirchner 1994; 163, 2019). Accordingly, co-enrollment does not place deaf children into hearing classrooms but brings together deaf and hearing children in an inclusive shared learning space. By educating a "critical mass" (approximately 20-25\%) ${ }^{\text {iv }}$ of deaf students alongside hearing ones, deaf students are no longer "the other" in co-enrollment programs. In practice, the co-enrollment programs surveyed around the world look different (see summary in Antia et al. 2019), but they all share this basic philosophy.

Co-enrollment was founded in 1982 through collaboration between American educator Carl J. Kirchner and the parents of a deaf child. TRIPOD, an acronym for Toward Rehabilitation Involvement by Parents of the Deaf, concentrated on the triad of rehabilitation services, parenting, and education (see Kirchner 1994, 2019). Co-teaching between a teacher of the deaf and a general education teacher was a core component of this original pedagogical approach to co-enrollment. ${ }^{v}$ Typically, co-teaching is carried out by a general education teacher and a teacher of the deaf. Co-teaching benefits both teachers and students. General education teachers tend not to be properly trained or experienced in educating deaf students since, due to the low incidence of deafness, they will have had few opportunities to develop effective strategies to teach deaf students (Antia et al. 2019), as seen in Japan (Forlin et al. 2015). General education teachers in co-enrollment environments, on the other hand, can develop pedagogical skills and insights through collaboration with specialist colleagues and daily exposure to deaf learners.

Language use and communication methods are central concerns in co-enrollment programs. Deaf students need to have total access to communication in the classroom to be placed on equal footing. In the TRIPOD program, the Total Communication philosophy, which is often confused with Simultaneous Communication (SimCom or simultaneous speech and sign), incorporates all forms of communication (formal sign language, speech, speech-reading, fingerspelling, reading, and writing) (Kirchner 2019 and personal communication). However, I argue that sign bilingual programs, which aim to give deaf students "the best of both educational worlds" (Marschark et al., 2014; 450), have the greatest potential for creating ibasho.

Sign bilingual co-enrollment programs do not yet exist in Japan. To my knowledge, co-enrollment has only been trialed once in the country (Torigoe 2013, 2019). Instead, there are currently four main placement options for deaf students in Japan: separate schools, "full inclusion" in general education classes without any support, ${ }^{\text {vi }}$ enrollment in separate classes with periodic attendance in mainstream spaces, and enrollment in general education classes with periodic "pull out" instruction in resource rooms. In the next section, I focus on the ab- 
sence of ibasho in general education classes, because it is in those environments where students most struggle to find belonging.

\section{Absence of Ibasho in "Hearing" Schools}

The fourth-grade teacher always had, right after recess, appreciation things. I like what you did during recess, I didn't [like what you did]. The deaf kids were, of course, a part of that. And the teacher would say, who do you appreciate? Who do you not appreciate? Well, I was in there this one day and one of my deaf kids got up and signed "I don't like you. You're not nice." And she called out the hearing kid, that she was not nice to her. I thought, "Yes! This is what we want. You stood up for yourself. You told the group, the hearing kid apologized. [The deaf student] was satisfied." I thought, "Okay, now we're really, really integrated."

(C. J. Kirchner, personal communication, Sept. 28, 2020)

In the episode from a TRIPOD program, relayed by Carl J. Kirchner, the term "integrated" is used. However, this anecdote serves as an example of not only social integration but of the existence of ibasho in a co-enrollment program. When the right conditions are established in a regular classroom (tsüjo gakkyū), it may shift from being a place where deaf children feel they must be (inakereba naranai basho) to one where they want to be (itai basho) (Fujimoto \& Torigoe, 2012, p115). Ibasho requires more than being a place one wishes to be; it should be a place where a student feels the right to be. Speaking up for herself demonstrated that the student felt she not only had the right to be in the classroom but the right to be treated well there. Further, she was able to communicate with and be understood by her classmates in an accessible shared language.

Throughout my initial fieldwork in 2012-2014, deaf people of all ages described "regular schools" as "hearing schools." What was unmarked or taken for granted (Zerubavel 2018) by majority (hearing) people was marked as a special hearing space by deaf people. If general education settings are "hearing" spaces, how can deaf students ever be expected to attain full membership? It was not only the nomenclature but also the retrospective accounts that pointed to discomfort in these spaces along with the absence of peer and self-acceptance. These findings aligned with international research, which has shown that deaf students in mainstream classes are more likely to be neglected and/or rejected by hearing classmates and less likely to be selected as friends (e.g., Nunes et al. 2001, Stinson \& Antia, 1999).

Hagiwara (2001) talks about a "lived body" (ikirareta shintai) and its connection to people, objects and the environment, noting that ibasho derive from "mutual recognition" (sogoshonin) between the self and others (p. 63). Yet deaf students in mainstream schools were not recognized or connected; they were neglected and isolated. International literature has referred to these solo students as "solitaires" (Oliva 2004) or "singletons" (Knoors \& Marschark 2012). Participants in my research regularly signed hitori botchi to describe both this solo status and the accompanying solitude. Schools were not ibasho but sites of overt and subtle exclusion, where they needed to develop strategies to cope with daily school life. 
Deaf people have been shown to engage in many "coping strategies" to "manage their everyday lives and protect their self-esteem" when negotiating hearing spaces (Jambor \& Elliot 2005; 67-68). Similarly, participants described and demonstrated behavior in mainstream schools which I categorized as concealing markers of difference (e.g., covering hearing aids), rejecting information support (e.g., turning down note-taking support) to avoid "standing out," performing "communicative competence" (i.e., passively and actively feigning mastery of spoken Japanese) and mimicking hearing peers (McGuire 2017; 2020). Although these efforts helped to mitigate difference, they did not negate the effects of social neglect or stress. ${ }^{\text {vii }}$ The most important relationships for school-aged children are their age-mates (Bamba \& Haight 2007); however, meaningful peer relationships were lacking. In sum, the requisites for ibasho ("peer group acceptance," "feeling a sense of belonging" and "contributing to the group" with a distinct role as well as self-expression) (Bamba \& Haight 2007:421; Kayama \& Haight 2014:13) were not experienced by the research participants.

Temporary ibasho could be found in hearing schools. Resource rooms ( $t s \bar{u} k y \bar{u}$ shido kyōshitsu), where students usually attend Japanese (kokugo), math, and English classes, were found to function as places to escape (nigeba) from the pressures of the regular class (McGuire \& Tokunaga 2020). In these spaces, deaf students could cease performative coping strategies, seek guidance from their support class teacher, and find sameness with deaf peers (albeit few in number) while being buffered from assimilative pressures. This temporary safe space was needed precisely because inclusion has not been achieved. The aforementioned study focused on the experiences of junior high school students; however, this type of support from the resource room teacher was also observed through fieldwork at an elementary school (Fujimoto \& Torigoe 2012). In the case of students enrolled in special self-contained units (tokubetsu shien gakkyū), with limited time in general education, they are, by design, partial members, not full members of the mainstream class. Whereas mainstreaming connotes the teacher as "gatekeeper" and the child as a "visitor" adapting to the regular classroom, inclusion connotes that classroom practices should be adjusted to accommodate individual children who are "members" of the regular classroom and therefore academically and socially integrated (Stinson \& Antia, 1999; 164-165). Co-enrollment aligns with inclusive education because it offers the potential for deaf students to become "true social members" of the class (Kreimeyer et al. 2000; 174).

\section{Ibasho in Co-Enrollment Settings}

\subsection{True Social Inclusion through "Equal Study"}

Co-enrollment offers both academic and social benefits. Academic performance can be linked to self-esteem and self-acceptance. However, my research showed that social inclusion was a more significant concern to deaf students and its absence the greatest barrier to ibasho. As such, I focus on the social benefits of co-enrollment, particularly those related to offsetting social isolation, developing a positive attitude toward deafness, and building self-esteem. Although this article views co-enrollment through the lens of ibasho for deaf children, it is important to note that co-enrollment is not for deaf children but for deaf and hearing chil- 
dren. Therefore, the social benefits should - and do-extend to both groups. Giving deaf and hearing students opportunities to develop sign language skills together results in a sense of familiarity and solidarity. Co-enrollment programs have been shown to increase deaf-hearing interactions (Kreimeyer et al. 2000) while "alleviat[ing] the social isolation" of deaf students (McCain \& Antia 2005; 30). This aligns with the true vision of co-enrollment, which is creating an environment where all students can learn together.

Deafness remains stigmatized in most societies, but "equal study" has had the effect of helping hearing children to develop a more egalitarian view of deaf people. For instance, an analysis of a co-enrollment program in a school district in the US indicated that co-enrollment experiences led to hearing students improving their sign language skills, views of deafness, and awareness of issues of "hearing loss" (Bowen 2002; 290). Similarly, a co-enrollment program in Italy found that hearing students were positively affected as they learned to see relationships with people different from them as a "source of personal enrichment," which the authors noted could be applied to interactions with people from other national backgrounds (Di Gregorio et al., 2019; p 168). Although these studies did not explicitly discuss ibasho, greater acceptance is a requisite for belonging. Further, to create a more inclusive society, linguistic differences should not be assimilated but embraced. Sign bilingual programs implicitly teach both deaf and hearing students to view sign language favorably.

\subsection{Sign Bilingual Co-Enrollment Approach}

Deaf children acquire Sign exactly as hearing children acquire a first spoken language; most can learn aural language in its written form as a second language. For many, however, speech is a mystical gymnastics of the tongue and throat, while lip-reading is a guessing game (Solomon, 2014; 53).

Although it has been said that combining sign language with spoken/written language is not a requirement of co-enrollment (Marschark et al., 2014), I contend that sign language is essential to facilitate meaningful communication (a requisite for deaf students' ibasho). As a visual-spatial language, sign language offers deaf students full access. They are not made to play the aforementioned lip-reading guessing game or to spend valuable study time learning to produce speech, which may or may not be intelligible to hearing people. Students who wish to speak may, but they do so without compulsion. In the Japanese context, JSL should be a language of direct communication and not one of mediated communication. For communication to be unmediated, everyone present needs to be able to sign. Therefore, I propose that sign bilingualism should be introduced to co-enrollment programs. "Sign bilingualism" typically refers to bilingualism in a sign language and a spoken language (although it can refer to fluency in two sign languages). If deaf and hearing teachers and students can sign, then interpreters become unnecessary.

Before discussing why sign bilingualism should be implemented in co-enrollment programs, I will first address why it is not sufficient for a co-enrollment program to employ an interpreter for the deaf students. Torigoe (2019) makes a distinction between "interpretation prominent" co-enrollment programs, such as the one he observed in Japan $(2013 ; 2019)$, and "co-teaching prominent" programs. His long-term observation of a co-enrollment program in 
a primary school revealed the barriers to ibasho in "interpreter prominent" programs. First, the students did not always understand the signs, nor did they have experience working with interpreters. They would forget to or fail to watch the interpreter, missing out on valuable information. The interpreters themselves were inexperienced in working with classroom interpretation (a common situation in Japan) and not familiar with interpreting for children. This raises a key question: how can students feel comfortable in a situation (with a sense of comfort being a requisite for ibasho) when the adults who are guiding them are not? In addition, the interpreters had to contend with information flow issues and uneasiness as to whether to intervene in group activities or how to manage information that bounced around the classroom. Critically, in this case, one of the cornerstones of co-enrollment, collaboration, was out of reach because the interpreters were hired on an hourly basis. (What occurred during the non-interpreted hours was not reported.) JSL was introduced to the hearing teachers and students, but they did not become sign fluent. Consequently, deaf students remained at a disadvantage as they could not receive the same quantity or quality of information, nor could they freely engage in meaningful communication. The use of sign interpreters cannot ensure social integration because the chance for students to develop relationships through unmediated and constant interactions has been taken away (Yiu \& Tang 2019; 361). To enable direct, unmediated communication among children in a co-enrollment classroom, hearing students must learn to sign (Kreimeyer et al., 2000). This co-enrollment program in Japan may have offered temporary ibasho, much like the resource rooms described in section three; however, their classroom was not a consistent or dependable site for fluid and spontaneous communication.

Studies on co-enrollment indicate that signing is the key to positive social outcomes for all students. In a sign bilingual environment, all children can learn together at the same time and have equal ability to participate in the classroom. As often noted, "physical proximity does not ensure effective social relationships" (Hintermair, 2014; 173). Having a mutually intelligible language, sign language, creates opportunities for unmediated communication between deaf and hearing children. Sign language can be considered a language of equality. Deaf and hearing children have equal access to visual-spatial languages. Further, due to the high number of deaf children who are raised by hearing parents, sign language is rarely the L1 at home (Tang et al. 2014), creating a situation in which deaf and hearing children may be introduced to sign language at the same time. This is not to say that deaf and hearing students are adding a sign language to the same linguistic repertoire. Hearing children are raised in acquisition-rich environments, whereas deaf children may lack linguistic input and have missed out on incidental learning opportunities. However, from the perspective of social integration, dual or multilingual input provides an important condition for ibasho.

The Chinese University of Hong Kong's Sign Bilingualism and Co-Enrollment program, SLCO, provides a model for sign language creating an inclusive setting with potential for ibasho (Tang et al. 2014; Tang 2017; Yiu \& Tang, 2014; Yiu et al., 2019). Deaf students in Hong Kong were educated in separate (special school) settings until a 1977 government White Paper promoting "integration" led to more students being enrolled in mainstream settings and educated through oral (spoken language) approaches (Yiu \& Tang, 2014). It was in the context of mainstream oral communication in which the SLCO program was established in 2006. 
The SLCO program took a "whole school approach" which involved deaf educators, the promotion of bimodal bilingual development, and the encouragement of full participation in all aspects of schooling (including extracurricular activities) (Yiu \& Tang, 2014; Yiu et al., 2019; Tang 2017). Sign bilingualism was not a stop on the road to oral communication; bimodal bilingual development was a goal for all members of the program. Deaf and hearing students had access to class content in speech, writing, and Hong Kong Sign Language.

Positive social outcomes were reported in the SLCO program. Deaf and hearing students rated one another favorably and interacted often (Yiu \& Tang 2014). In their assessment of social integration, Yiu and Tang (2014) measured deaf and hard-of-hearing students' acceptance of a deaf identity, reactions to worries and frustrations, optimism related to coping, and readiness for social contact. They found that deaf and hard-of-hearing students had "quite positive and optimistic attitudes toward their hearing loss" (Yiu and Tang, 2014; 355). However, they did note that acceptance of their deaf identity improved more slowly over time. Further, their results on hearing peers' attitudes toward deaf and hard-of-hearing students showed that they viewed their deaf peers positively and demonstrated a willingness to support them. On the other hand, Yiu and Tang did note that the hearing students took time to develop an understanding of deaf and hard-of-hearing students' communication difficulties. Duration appeared to be a key factor. In other words, the longer a deaf or hard-of-hearing student was in the SLCO, the higher their rating from hearing peers.

The success of sign bilingual programs is closely linked to the language fluency of all classroom members. Upon reviewing co-enrollment programs, Tang (2017) concludes that the overall success relies on deaf and hearing participants (students and teachers) becoming bimodal bilinguals (i.e., fluent in two languages in two modes, signed and spoken). Further, the acquisition of signing skills appears to directly link to acceptance. Learning to sign has been shown to create positive views toward deaf students. For instance, in one US study, hearing students with the weakest signing skills had the most negative views of deaf and hard-ofhearing students (Bowen 2008). In the SLCO program, it was not spoken language abilities but signing and self-acceptance that created mutual acceptance among deaf and hearing students (Yiu \& Tang, 2014). Students who signed well were rated well. In a sign bilingual environment, all students are aiming to be bimodal bilinguals. When deaf students accepted their deafness, they rated other deaf students higher and received higher ratings from hearing peers (Yiu \& Tang, 2014).

\subsection{Developing a Positive Self-Identity in Sign Bilingual Settings}

Deaf people in society face stigmas, barriers, pathologizing views, and indifference. Under these circumstances, forming positive self-esteem is challenging (Mousavi et al. 2017) and support is needed particularly when a child is born to hearing parents (Yiu \& Tang 2014). As noted, deaf children are statistically unlikely to have deaf role models at home. Sign bilingual co-enrollment learning environments may help deaf students to develop a positive bi-cultural identity, especially when there is a deaf adult in the classroom.

Deaf educators play an important role in developing a positive identity. Since adults with bicultural identities were found to have the most positive attitudes toward deaf people 
(of all backgrounds), it has been argued that introducing deaf students with "hearing identities" (common in students from hearing families who attend mainstream schools) to deaf peers and role models would have a psychological benefit (Bat-Chava 2000). Sign bilingual programs such as the SLCO program in Hong Kong show deaf teachers teaching in collaboration with hearing teachers. As Yiu and Tang note (2014), including deaf teachers "is not solely for bringing sign language into the classroom, but also for setting up that teacher as a model and a link to the Deaf community" (p. 363).

Sign bilingual co-enrollment programs can also foster a positive self-identity when they celebrate deaf students' signing skills. In one co-enrollment program in the US, the deaf and hard-of-hearing students were deemed "signing specialists" and their proficiency was made known to all students (Kreimeyer et al. 2000). As a result of this reframing, instead of being judged on their oral communication skills, which automatically places deaf students behind their hearing peers, they were held up as linguistic models. A co-enrollment program in Italy observed that when deaf children from regular schools joined the program, the ability to interact with deaf and hearing peers along with a "positive adult model" helped them to develop their self-confidence (Di Gregorio et al., 2019; 180). I argue that a truly inclusive educational environment is one in which deaf students can enjoy a positive self-identity without the pressure to assimilate to mainstream audist norms.

\section{Challenges and Considerations in Co-Enrollment}

To position co-enrollment as an uncomplicated answer to inclusive education would be to obscure the diversity of deaf experiences and to gloss over the inherent difficulties in implementing these programs. Co-enrollment programs are found worldwide, but are not widespread because there are challenges and considerations for implementing effective co-enrollment. These challenges can be broadly categorized as administrative challenges, pedagogical challenges, and linguistic challenges.

The most significant administrative challenges are related to expenses and to student populations. In discussing the situation in the US, Carl J. Kirchner noted that although it is less costly to have deaf children in a co-enrollment program than in a self-contained classroom, it is difficult to convince the budget teams (personal communication, Sept. 28, 2020). Would Japanese school boards be similarly skeptical? Further, the need for a "critical mass" raises concerns. What would occur in rural areas with few deaf students? Parents and children may, understandably, be opposed to the idea of bussing to a central school because it could separate deaf children from other neighborhood children.

Collaborative pedagogies are similarly complex. Co-teachers need to be fully committed to the mission and willing to engage in a high degree of collaboration. Although not ideal for ibasho, in an interpreter-mediated program, the interpreter would have to be integrated in the process. As mentioned, the interpreters involved in the program in Japan observed by Torigoe (2019) were only able to participate on a limited basis which meant true collaboration was never possible. For a sign bilingual co-enrollment program with deaf role models to be a 
success, considerations must be made of sign language training and education on deafness and collaborative teaching (Tang, 2017). Further, teachers of deaf students must overcome the inclination to work with deaf students, which would result in "de facto segregating rather than integrating the classroom" (Antia et al. 2019; 17). A related pedagogical challenge is that hearing students may catch up with language, but there is no guarantee that the adults, specifically the hearing general educator, can or will develop sign language proficiency.

Another pedagogical challenge is imparting instruction to students who have different sensorial accessibilities and linguistic profiles. First, when spoken and signed languages are taught in parallel, deaf children need to follow instructions at all times with their eyes, but hearing students can continue to work while listening to oral instruction, producing "differences in rhythms" between the groups (Ghesquière \& Meurant 2019; 224). Differences in working speeds have been known to lead to hearing children making fun of deaf children (Kirchner 1994; 164). Second, even if all instruction is signed, there may be unequal access because deaf students may have very different linguistic profiles before beginning school, depending on their family of origin. Linguistic profiles may vary from deaf children with language deprivation syndrome who, due to being denied an accessible first language, have no meaningful language during a critical period, (Hall, 2017) to sign fluent children from deaf families. As a consequence, it is critical to ascertain the type of family, hearing or deaf, experience with speech therapy and knowledge of sign language (Di Gregorio et al., 2019; 173).

In addition to the in-class challenges inherent in carrying out a co-enrollment program, parental attitudes may also need to be considered. Sign bilingual co-enrollment programs rely on the cooperation of parents and guardians. Due to deafness being stigmatized in Japan, parents of hearing children may be hesitant to have their child enrolled in a class with a number of deaf children. At the same time, the TRIPOD program in the US points to the possibility for shifts in perception. Following a period of initial skepticism, the program quickly became popular, with a list of parents of hearing children signing up after recognizing the pedagogical benefits of having two teachers in the classroom (Carl J. Kirchner, personal communication, Sept. 28, 2020).

\section{Conclusion}

The first co-enrollment program, the TRIPOD program, was family-centered. It came to fruition because of the commitment of dedicated parents of deaf children who joined committees and continued to make requests for educational opportunities for their children. When the first preschool program opened in 1984, ${ }^{\text {viii }}$ hearing siblings were a "key component" of the cohort (Kirchner, 2019; 27). Parents and siblings were offered opportunities to take sign language classes at home or at school (Kirchner 2019). Similarly, a number of co-enrollment programs throughout the world have been requested and initiated by parents. While this article focused on the school experiences, research suggests that the direct engagement of (hearing) parents in their deaf child's education and the potential for deaf children to communicate via sign language with parents and siblings could strengthen connections, thereby 
shifting the home from a site of isolation to an ibasho.

Educational experiences can have long-term effects on the self-esteem of marginalized students. All students should be positioned as members - not visitors - within their classrooms and their schools. Yet deaf students in mainstream schools are often socially and linguistically isolated because of embodied difference and communication barriers. Due to the "critical mass" of deaf students, the co-enrolled classroom is no longer an exclusive hearing one but an inclusive one with deaf peers and role models. Language plays an important role in fostering inclusivity. The interpreter-mediated program observed in Japan (Torigoe 2013; 2019) fits the more flexible definition of "co-enrollment" but appears to fall short on offering a place to develop an ibasho due to the challenges of learning and socializing via part-time interpretation.

On the other hand, sign bilingual co-enrollment programs have been shown to create environments where students learn equally, embodying the true meaning of "equal study." Sign language goes from being an unknown language for deaf people to a part of "common linguistic resources for classroom learning and social interactions between the Deaf and hearing participants" (Tang, 2017; 200). When deaf teachers are employed, they are not only educators but deaf adult role models for deaf youth, most of whom lack such models in hearing families. The positive aspects of these bilingual-bicultural environments are experienced by hearing and deaf students. A pedagogical program designed to accommodate deaf students had the unintended effect of bolstering deaf and hearing students' acceptance of one another (Yiu and Tang, 2014; 364). This embodies the true meaning of inclusion. Inclusive education is not for students with so-called "differences" but for all students to learn and grow together, equally. Hearing children are shown to value deaf classmates and view them as members of the classroom. More longitudinal research on alumni of these programs is needed; however, it is hoped that early childhood connections during school days could lead to an appreciation and acceptance of difference in society.

Although it is difficult to generalize a small number of studies with relatively small sample sizes, the current research points to sign bilingual co-enrollment programs as potential pathways to ibasho in mainstream schools. Respecting deaf students' rights to an education in a fully comprehensible language in an inclusive setting should be a baseline. As such, challenges should not be framed as reasons for eliminating co-enrollment as a pedagogical possibility but instead considered as topics of further discussion and debate among deaf and hearing teachers, policy-makers, parents, and other professionals who work with deaf children. Such discussions and debates should be extended to interested parties who work with marginalized students. As I stated in the introduction, deaf students have a distinct profile due to their claims to linguistic rights and cultural belonging. Therefore, the bilingual co-enrollment model cannot be easily applied to students with other disabilities. However, lessons from co-enrollment programs have potential applicability for educators, policy-makers, parents, and professionals interested in improving social inclusion in the classroom. Such applications may become especially relevant when guiding and supporting strategies to create full membership in the classroom. Classroom membership is therefore a benefit available to not only students with disabilities but to more generally marginalized students who may experi- 
ence an absence of ibasho in the general classroom.

When recognizing the ethnic Japanese majority as "unnamed" and "invisible" in education (Takahashi 2020), it is also important to problematize the experiences of marked students within this unmarked majority. Ethnically Japanese deaf students are one such group. Despite cultural and linguistic features, deaf students' experiences are frequently absent in analyses of multiculturalism in Japanese education (e.g., Hirasawa 2009; Tsuneyoshi et al. 2011). To include them in discourse on multicultural education would be to move away from the deficit model and toward an understanding of deaf children as members of a linguistic minority group. Sign bilingual co-enrollment programs as culturally inclusive spaces that respect linguistic differences hold real potential to forge pathways to ibasho in deaf education.

\section{Notes}

i A notable exception to this general pattern is children born into signing deaf families where sign language, traditions, and deaf culture can be passed down intergenerationally without complication.

ii Deaf education may be infused with so-called "Japanese-ness," but Japan's educational history is part of transnational shifts in pedagogies and language perceptions because the spread of deaf education was promoted through "the transnational circulation of ideas and practices" (Cleall, 2015; 2). It is precisely because of these continuing transnational flows that contrasts and comparisons can be made with vastly different societies in a way that could not be done with general education.

iii These two signs originated in Japan. During a visit to Japan in the late 1980s to lecture about co-enrollment, Carl J. Kirchner, was asked for the ASL sign. Up until that point, they had been fingerspelling the word. Kirchner asked the Japanese participant how he would sign "co-enrollment." Although co-enrollment has yet to take hold in Japan, it influenced co-enrollment worldwide as the JSL sign was brought back to the US and adopted as the sign for "co-enrollment." (C. J. Kirchner, personal communication, Sept. 28, 2020).

iv In their checklist for the "fidelity" of co-enrollment programs, Antia and Metz suggest 20-25\% as a possible figure $(2014 ; 439)$, while Marchark notes that "ideally, if rarely" it should be "at least 25\%" (2018; 156).

$\mathrm{v}$ Deaf students follow the same curriculum as hearing students (with expansion when necessary) and are held to the same standards. Historically, while deaf children in separate schools have not been challenged to achieve high academic standards (often because precious class time is devoted to oral communication training), students in co-enrolled environments are met with high expectations (Kirchner 2019).

vi As Torigoe (2019) reminds us, students who receive no additional accommodations are not officially counted in the system.

vii Deaf students who found belonging tended to do so outside of the mainstream classroom in extracurricular activities, particularly sports teams.

viii The program was incorporated in 1982 but did not commence its preschool program until 1984 .

\section{References}

Antia, S., Knoors, H., \& Marschark, M. (2019). Co-enrollment and the education of deaf and hard-ofhearing learners: Foundations, implementation, and challenges. In M. Marschark, S. Antia \& H. Knoors (eds.), Co-enrollment in deaf education (pp. 1-24). New York: Oxford University Press.

Antia, S., \& Metz, K.K. (2019). Co-enrollment in the United States: A critical analysis of the benefits and challenges. In M. Marschark, S. Antia \& H. Knoors (eds.), Co-enrollment in deaf education (pp. 424-441). New York: Oxford University Press.

Bamba, S., \& Haight, W. L. (2007). Helping maltreated children to find their ibasho: Japanese per- 
spectives on supporting the well-being of children in state care. Children and Youth Services Review, 29(4), 405-427.

Bat-Chava, Y. (2000). Diversity of deaf identities. American Annals of the Deaf, 145(5), 420-428. Retrieved from doi:10.1353/aad.2012.0176

Bowen, S. K. (2008). Coenrollment for students who are deaf or hard of hearing: Friendship patterns and social interactions. American Annals of the Deaf, 153(3), 285-293.

Cleall, E. (2015). Deaf Connections and Global Conversations: Deafness and education in and beyond the British Empire, ca. 1800-1900. Journal of Colonialism and Colonial History, 16(1).

Di Gregorio, L., Campana, V., Lavecchia, M., \& Rinaldi, P. (2019). Include to grow: Prospects for bilingual and bicultural education for both deaf and hearing students. In M. Marschark, S. Antia \& H. Knoors (eds.), (pp. 165-181). New York: Oxford University Press.

Forlin, C., Kawai, N., \& Higuchi, S. (2015). Educational reform in Japan towards inclusion: Are we training teachers for success? International Journal of Inclusive Education, 19(3), 314-331.

Fujimoto, Y., \& Torigoe, T. (2012). Nanchō gakkyū ni zaiseki shite iru chōkaku shōgai jidō no communication to shien - kōryū gakkyū ni okeru 'ibasho' no shiten kara (Communication of hard-ofhearing pupils and their support in an inclusive classroom: From the viewpoint of 'Ibasho'). $G a-$ kkō Kyōiku-Gaku Kenkyū (The Journal of School Research), 24, 109-116. (Japanese)

Ghesquière, M., \& Meurant, L. (2019). Conditions for effective co-enrollment of deaf and hearing students: What may be learned from experiences in Belgium. In M. Marschark, S. Antia \& H. Knoors (eds.), Co-enrollment in deaf education (pp. 211-233). New York: Oxford University Press.

Hagiwara, K. (2001). Kodomo wakamono no ibasho no jōken (Conditions for children's and youth's ibasho). In H. Tanaka (ed.), Kodomo wakamono no ibasho no kōsō: "Kyoiku" kara "kakawarinoba" e (Ibasho for children and youth: From "education" to "a place for interaction" (pp. 5165). Tokyo: Gakuyo Shobo. (Japanese)

Hall, W. C. (2017). What you don't know can hurt you: The risk of language deprivation by impairing sign language development in deaf children. Maternal and Child Health Journal, 21(5), 961965.

Hauser, P., O’Hearn, A., McKee, M., Steider, A., \& Thew, D. (2010). Deaf Epistemology: Deafhood and Deafness. American Annals of the Deaf, 154(5), 486-492.

Hintermair, M. (2019). Psychosocial development in deaf and hard-of-hearing children in the twenty-first century: Opportunities and challenges. In M. Marschark, S. Antia \& H. Knoors (eds.), Co-enrollment in deaf education (pp. 152-186). New York: Oxford University Press.

Hirasawa, Y. (2009). In J. A. Banks (ed.) The Routledge International Companion to Multicultural Education (159-169). New York: Routledge.

Jambor, E., \& Elliott, M. (2005). Self-esteem and coping strategies among deaf students. The Journal of Deaf Studies and Deaf Education, 10(1), 63-81.

Kayama, M., \& Haight, W. L. (2014). Disability, culture, and development: A case study of Japanese children at school. New York: Oxford University Press.

Kirchner, C. J. (1994). Co-enrollment as an Inclusion Model. American Annals of the Deaf, 139(2), 163-164.

Kirchner, C. J. (2019). TRIPOD: Answer to the seeds of discontent. In M. Marschark, S. Antia \& H. Knoors (eds.), Co-enrollment in deaf education (pp. 25-40). New York: Oxford University Press.

Knoors, H., \& Marschark, M. (2012). Language planning for the 21st century: Revisiting bilingual language policy for DHH students. Journal of Deaf Studies and Deaf Education, 17(3), 291-305.

Kreimeyer, K. H., Crooke, P., Drye, C., Egbert, V., \& Klein, B. (2000). Academic and social benefits of a co-enrollment model of inclusive education for deaf and hard-of-hearing children. Journal of Deaf Studies and Deaf Education, 5(2), 174-185.

Marschark, M. (2018). Raising and educating a deaf child: A comprehensive guide to the choices, controversies, and decisions faced by parents and educators. New York: Oxford University Press.

Marschark, M., Knoors, H., \& Tang, G. (2014). Perspectives on bilingualism and bilingual education 
for deaf learners. In M. Marschark, G. Tang \& H. Knoors (eds.), Bilingualism and bilingual deaf education (pp. 445-476). New York: Oxford University Press.

McCain, K. G., \& Antia, S. D. (2005). Academic and social status of hearing, deaf, and hard of hearing students participating in a co-enrolled classroom. Communication Disorders Quarterly, 27(1), 20-32.

McGuire, J. M. (2017). "Inte" at intersections: Deaf and hard-of-hearing mainstreamed Japanese youth and the search for belonging [Unpublished doctoral dissertation]. University of Oxford.

McGuire, J.M. (2020). Who am I with others?: Selfhood and shuwa among mainstream educated deaf and hard-of-hearing Japanese youth. Contemporary Japan, 32(2),197-217.

McGuire, J.M. \& Tokunaga, T. (2020). Co-constructing Belonging: 'Voluntary Separation' in Deaf and Immigrant Education in Japan, Japanese Studies, 40(3), 291311.

Meek, D. R. (2020). Dinner table syndrome: A phenomenological study of deaf individuals' experiences with inaccessible communication. The Qualitative Report, 25(6), 1676-1694.

Mithout, A. L. (2016). Children with disabilities in the Japanese school system: A path toward social integration? Contemporary Japan, 28(2), 165-184.

Mousavi, S.Z., Movallali, G., \& Mousavi Nare, N. (2017). Adolescents with deafness: A review of self-esteem and its components. Aud Vestib Res, 26(3), 125-137.

Murray, J. J., De Meulder, M., \& Le Maire, D. (2018). An education in sign language as a human right?: The sensory exception in the legislative history and ongoing interpretation of article 24 of the UN convention on the rights of persons with disabilities. Human Rights Quarterly, 40, 37-60.

Nunes, T., Pretzlik, U., \& Olsson, J. (2001). Deaf children's social relationships in mainstream schools. Deafness and Education International, 3(3), 123-136.

Oliva, G. A. (2004). Alone in the mainstream: A deaf woman remembers public school. Washington, DC: Gallaudet University Press.

Solomon, A. (2014). Far from the tree: Parents, children and the search for identity. London: Vintage Books.

Stinson, M. S., \& Antia, S. D. (1999). Introduction: Considerations in educating deaf and hard-ofhearing students in inclusive settings. Journal of Deaf Studies and Deaf Education, 4(3), 163175.

Takahashi, F. (2020). Japaneseness in immigrant education: Toward culturally responsive teaching in Japan. Educational Studies in Japan, 14, 15-27.

Tang, G. (2017). Sign Bilingualism in Deaf Education. In O. García, A.M.Y. Lin \& S. May (eds.), Bilingual and Multilingual Education, $3^{\text {rd }}$ Edition (191-203). Cham, Switzerland: Springer International Publishing.

Tang, G., Lam, S., \& Yiu, K.C. (2014). Language development of deaf children in a sign bilingual and co-enrollment program. In M. Marschark, G. Tang \& H. Knoors (eds.), Bilingualism and bilingual deaf education (pp. 313-341). New York: Oxford University Press.

Torigoe, T. (2013). Chōkaku shōgai-ji no inclusive kyōiku no tenkai (3): Nanchō gakkyū o motsu kōritsu shōgakkō de no shuwa dōnyū katsuyō no kokoromi (Development of inclusive education for deaf and hard-of-hearing children (3): An attempt of signed language implementation to the primary school which had self-contained special classes for hard-of-hearing pupils in Japan). Hyōgokyōikudaigaku Kenkyū Kiyō (Hyogo University of Teacher Education Journal), 43, 37-49. (Japanese)

Torigoe, T. (2019). Learning together by deaf and hearing students in a Japanese primary school. In M. Marschark, S. Antia \& H. Knoors (eds.), Co-enrollment in deaf education (pp. 69-81). New York: Oxford University Press.

Tsuneyoshi, R. K., Okano, K. H., \& Boocock, S. S. (2011) (eds.), Minorities and education in multicultural Japan: An interactive perspective. London: Routledge.

World Federation of the Deaf (WFD). "Human Rights." Accessed December 29, 2020. https://wfdeaf. org/our-work/human-rights-of-the-deaf/

Yiu, C. K., Tang, G., \& Ho, C. C. (2019). Essential ingredients for sign bilingualism and co-enroll- 
ment education in the Hong Kong context. In M. Marschark, S. Antia \& H. Knoors (eds.), Co-enrollment in deaf education (pp. 83-106). New York: Oxford University Press.

Yiu, K. C., \& Tang, G. (2014). Social integration of deaf and hard-of-hearing students in a sign bilingual and co-enrollment environment. In M. Marschark, G. Tang \& H. Knoors (eds.), Bilingualism and bilingual deaf education (pp. 342-367). New York: Oxford University Press.

Zerubavel, E. (2018). Taken for granted: The remarkable power of the unremarkable. Princeton: Princeton University Press. 